\title{
Workplace Violence Among Healthcare Workers in a Tertiary Medical City in Riyadh: A Cross- Sectional Study
}

Fares F. Alharbi 1, 2, 3 , Nowar A. Alzneidi ${ }^{4}$, Ghaida H. Aljbli ${ }^{5}$, Sarah A. Morad ${ }^{6}$, Ettab G. Alsubaie ${ }^{2,} 3$, Mahmoud A. Mahmoud ${ }^{7}$, Sami A. Al-Dubai ${ }^{8}$, Firas A. Nakshabandi ${ }^{9}, 10$, Saleh bin Saleh 1, 11, 3

1. College of Medicine, King Saud Bin Abdulaziz University for Health Sciences, Riyadh, SAU 2. Department of Mental Health, Ministry of the National Guard Health Affairs, Riyadh, SAU 3. Department of Research Office, King Abdullah International Medical Research Center, Riyadh, SAU 4. Department of Family Medicine, King Khalid University Hospital, Riyadh, SAU 5. Department of Plastic Surgery, Ministry of the National Guard Health Affairs, Riyadh, SAU 6. Department of Pediatrics, King Fahad Medical City, Riyadh, SAU 7. Department of Public Health, Imam Muhammad Ibn Saud Islamic University, Riyadh, SAU 8. Joint Program of Preventive Medicine Post Graduate Studies, Saudi Ministry of Health, Medina, SAU 9. Department of Psychiatry and Behavioral Neuroscience, The University of Chicago, Chicago, USA 10. Mental Health Department, Empathic Resonance, LLC, Chicago, USA 11. Department of Medicine, Ministry of the National Guard Health Affairs, Riyadh, SAU

Corresponding author: Fares F. Alharbi, faris137@hotmail.com

\section{Abstract}

\section{Introduction}

Workplace violence is a common problem that is encountered by healthcare workers worldwide; however, it is still under-studied in Saudi Arabia. This study aims to determine the prevalence of workplace violence and to explore reasons for not reporting it among healthcare workers in a tertiary medical city in Riyadh.

\section{Methods}

This cross-sectional study was conducted among 404 healthcare workers who had direct contact with patients or their relatives in a tertiary care medical city in Riyadh, Saudi Arabia. Data were analyzed using Statistical Analysis Software Package (SPSS; IBM, Armonk, NY, USA).

\section{Results}

Most participants (81.4\%) had experienced verbal, physical, academic, or sexual violence. Approximately $39.6 \%$ of those who experienced workplace violence did not report the incident, and the most common reason for not reporting was identified as "reporting would not accomplish anything" (49.4\%). About 27.5\% of violence victims did not know how to report the incidents. Patients or their relatives were the main sources of violence across all violence categories except academic violence, in which consultant physicians were the main source.

Review began 04/20/2021 Review ended 04/23/2021 Published 05/04/2021

(c) Copyright 2021 Alharbi et al. This is an open access article distributed under the terms of the Creative Commons Attribution License CC-BY 4.0., which permits unrestricted use, distribution, and reproduction in any medium, provided the original author and source are credited.

\section{Conclusions}

The prevalence of workplace violence in the population studied was higher than anticipated compared to similar studies both in Saudi Arabia and globally. Almost half of those who were subjected to violence did not report the incident, believing that reporting would not change anything. There is arguably an urgent need to develop strategies that reduce workplace violence and facilitate reporting it in hospitals. Moreover, awareness programs regarding the negative impacts of violence against healthcare workers on the quality of care are necessary.

Categories: Psychiatry, Public Health, Epidemiology/Public Health

Keywords: violence, sexual harassment, health personnel, workplace, saudi arabia

\section{Introduction}

Violence against healthcare workers is associated with various psychological, physical, and occupational impacts that may affect the quality of the provided care. Anxiety [1], depression [1], post-traumatic stress disorder (PTSD) [2], and burnouts [2] were all reported among healthcare workers as psychological consequences of workplace violence. Physical symptoms were also reported after exposure to violent incidents; these include pain, headache, and stomach ache [3]. Also, up to $65 \%$ of healthcare workers sustained physical injuries due to workplace violence, and some of the victims required medical treatment [3]. Lacerations, bites, abrasions, and bruises were all consequences of physical workplace violence [3]. Being subjected to violence also affects the victims occupationally; it is associated with decreased productivity [4], decreased job satisfaction [5], increased absence [6], and the intention to quit the job [7]. 
Violence against healthcare workers is a global problem [8]. In a recent review, the 12-month prevalence of violence against healthcare providers was found to be $70.9 \%$ in Australia and New Zealand, 67.3\% in North America, 64.9\% in Asia, 62.7\% in Latin America, 59.2\% in Africa, and 48.1\% in Europe [8]. Non-physical violence (42.5\%) was more common than physical violence $(24.4 \%)$, with verbal abuse $(57.6 \%)$ being the most common type of non-physical violence and sexual harassment $(12.4 \%)$ the least common [8].

There are a number of studies that examined workplace violence among healthcare workers in Saudi Arabia [9-16]. However, most of these studies were limited to a specific occupation like nursing [9,10], or a specific healthcare setting like emergency departments $[11,12]$ or primary care centers $[13,14]$. To the best of our knowledge, there are only two Saudi studies that addressed workplace violence among all healthcare workers without being limited to a specific department or healthcare setting $[15,16]$. The first study was conducted in Arar city by Al Anazi et al., which found that there was a $48.6 \%$ prevalence of workplace violence among healthcare workers working in general hospitals and primary care centers [15]. The second study was in Abha City, where the prevalence of workplace violence was found to be 57.5\% [16]. Despite the high rates of workplace violence in Saudi Arabia, the prevalence of reporting violent incidents ranged from $1.7 \%$ [14] to $38.5 \%[12]$.

Due to the aforementioned negative consequences of workplace violence, there is arguably an urgent need to identify the extent of workplace violence among a broader range of healthcare providers across a wider range of settings in Saudi Arabia. Also, identifying reasons that prevent victims from reporting violent incidents can promote the development of workplace policies that facilitate reporting. Thus, the aim of this study is to determine the prevalence of workplace violence amongst all healthcare workers in a tertiary medical city in Riyadh and to identify the reasons behind not reporting incidents of violence. To the best of our knowledge, this is the first study in Riyadh that examines workplace violence among all healthcare workers in a tertiary medical city without being limited to a specific department or occupation.

\section{Materials And Methods}

\section{Study participants, settings, and sample size}

This cross-sectional study included all health care providers that have direct contact with patients or their relatives in a tertiary medical city in Riyadh, Saudi Arabia. The medical city includes medical and surgical wards, pediatric wards, intensive care units, a cardiac center, an emergency and trauma department, obstetrics and gynecology services, antenatal and postpartum wards, rehabilitation and long-term care wards, outpatient clinics, and dental services. It also includes 11 primary healthcare centers that are distributed around different neighborhoods in Riyadh. Moreover, it is designated as a military medical city, providing care to the Saudi national guard members, their families, and other eligible individuals.

For a population size of 5,447 employees, the optimal sample size to obtain results within a margin of error of $5 \%$ and a confidence level of $95 \%$ was identified as 359 employees $(n=359)$. However, the questionnaire was given to 450 employees to ensure a better response; 404 questionnaires were returned with a response rate of $89.8 \%$. All participants were aware of the study objectives and signed a consent form before filling out the questionnaire.

\section{Data collection method}

A self-administered survey was distributed to healthcare workers in a tertiary medical city in Riyadh, Saudi Arabia from July 1, 2019 to October 1, 2019. The survey was conducted in English because it is the language spoken by all the staff. The survey was adapted from a previously published and validated study [17]. It includes seven sections: 1) demographics, 2) verbal violence, 3) physical violence, 4) academic violence, 5) sexual harassment, 6) reasons for not reporting violence, and 7) the influence of violence on the participants. The definition of verbal violence included shouting, humiliating, or speaking to the person in an un-respectful manner. Physical violence was defined as any threat that could cause physical injuries like hitting, pushing, or slapping. The definition of academic violence was being pressured to do personal services that are not related to the duties of the employee. Sexual harassment was defined as being subjected to repeated staring, comments or jokes against gender or body figure, or inappropriate touching of a sexual nature. It also includes being offered unwanted gifts with sexual underpinnings [17]. This study was IRBapproved by King Abdullah International Medical Research Center (IRB no. RYD-18-419812-203457). Informed consent was obtained from the participants.

\section{Data management and analysis}

Data were analyzed by using the SPSS (Statistical Analysis Software Package) program version 22 (IBM, Armonk, NY, USA). Descriptive analysis was employed to obtain the mean and standard deviation (SD) for the continuous variables and to obtain the frequency and percentage for the categorical variables. P-value was considered statistically significant if $\mathrm{P}<0.05$.

\section{Results}

Socio-demographic characteristics of the participants 


\section{Cureus}

In this study, the age range of the participants was 24-69 years old, with a mean of 36.9 years old and an SD of 8.5 years. Most participants were $>35$ years old (52.5\%), females (65.1\%), Saudis (54.0\%), and nurses (39.1\%). Most of them had an experience of six years or more (78.2\%) and have been working at the current hospital for six years or more $(60.1 \%)$ (Table 1$)$. 


\section{Cureus}

Variables

No. (\%)

Age

$\leq 35$

$>35$

Gender

Male

Female

Nationality

Saudi

Arab

Asian

Job title

Physician

Nurse

Administrator

Technician

Other

Specialty

Surgery

Medicine

Pediatrics

Obstetrics and gynecology

Emergency

Intensive care

Psychiatry

Other

Years of experience

1 to 2 years

3 to 5 years

6 years or more

How many years you have been working at this hospital?

1 to 2 years

3 to 5 years

6 years or more
137 (33.9)

158 (39.1)

49 (12.1)

$192(47.5)$

212 (52.5)

141 (34.9)

263 (65.1)

$218(54.0)$

38 (9.4)

148 (36.6)

37 (9.2)

23 (5.7)

6 (1.5)

123 (30.4)

76 (18.8)

36 (8.9)

23 (5.7)

22 (5.4)

38 (9.4)

79 (19.6)

38 (9.4)

$50(12.4)$

316 (78.2)

67 (16.6)

94 (23.3)

$243(60.1)$

TABLE 1: Sociodemographic characteristics of the participants $(n=404)$.

\section{Verbal violence among participants}

Verbal violence was reported by $79.5 \%$ of the participants. The most common type of verbal abuse was

"Someone was Inappropriately nasty, rude, or verbally hostile to them" (69.1\%) and "Someone spoke to 


\section{Cureus}

them un-respectfully" (67.8\%). The main sources of verbal violence were patients or their relatives (60.1\%) and consultants (45.5\%). Verbal violence has happened more frequently in the emergency (40.3\%) and obstetrics and gynecology departments (32.9\%). The majority had witnessed an episode of verbal violence, and they reported that both males and females were frequently verbally harassed (56.7\%). The majority (42.3\%) of the participants reported that their experiences with verbal violence were very upsetting and of major importance (Table 2). 


\section{Cureus}

\section{Variables}

No. (\%)

Experienced verbal violence

321 (79.5)

Did you experience any of the following types of "verbal violence"?

Someone shouted at you

Someone was Inappropriately nasty, rude, or verbally hostile to you

$279(69.1)$

Someone belittled or humiliated you during meetings or rounds

$178(44.1)$

Someone was joking at you

148 (36.6)

Someone spoke to you un-respectfully

$274(67.8)$

Others

$30(7.4)$

None of the above

$83(20.5)$

In which department/s these types of verbal violence have happened more frequently?

Surgery

78 (20.5)

Medicine

73 (19.2)

Pediatrics

40 (10.5)

Oblgyn

125 (32.9)

Emergency

$153(40.3)$

ICU

51 (13.4)

Psychiatry

$14(3.7)$

Other

$80(21.1)$

Who was/were the main source/s of verbal violence?

Consultant

184 (45.5)

Specialist/registrars

$10(2.5)$

Residents

116 (28.7)

Nurses

$61(15.1)$

Patients or their relatives

$243(60.1)$

During your career, have you witnessed any episodes of verbal violence?

Yes

No

47 (11.6)

From your experience, who is, in general, most frequently verbally harassed?

Male

Female

$125(30.9)$

Both

$229(56.7)$

If you experience any form of verbal violence, do you describe this/these experience/s as being very upsetting and of major importance?

Yes, all of them

Yes, some of them

196 (48.5)

No, not all

36 (8.9)

TABLE 2: Verbal violence among participants $(n=404)$. 


\section{Cureus}

\section{Physical violence among participants}

Physical violence was reported by $67.6 \%$ of the participants. About one-third of the participants had been threatened with physical harm (33.4\%), and $26.0 \%$ had been subjected to a slap, push, hit, kick, or having things thrown at them. About $25.7 \%$ had been placed at unnecessary medical risk. Physical violence had occurred more frequently in the emergency (18.1\%) and surgery departments (16.6\%). The main sources of physical violence were patients or their relatives (32.9\%) and consultants (13.4\%). During their career, 80.7\% of the participants had witnessed an episode of physical violence, and they reported that both males and females $(54.9 \%)$ were frequently physically harassed. The majority (50.7\%) of the participants reported that their experiences with physical violence were very upsetting and of major importance (Table 3). 


\section{Cureus}

Variables

No. (\%)

Experienced physical violence

$273(67.6)$

Did you experience any of the following types of physical violence?

Someone threatened you with physical harm

$135(33.4)$

slap, push, hit, kick or having things thrown at you

$105(26.0)$

Someone placed you at unnecessary medical risks

104 (25.7)

Others

95 (23.5)

non-of the above

$131(32.4)$

in which department/s these types of physical violence have happened more frequently?

Surgery

Medicine

Pediatrics

Oblgyn

Emergency

ICU

$18(4.5)$

Psychiatry

$5(1.2)$

Other

Who was/were the main source/s of physical violence?

Consultant

Specialist/registrars

$1(0.2)$

Residents

$25(6.2)$

Nurses

Patients or their relatives

$133(32.9)$

During your career, have you witnessed any episodes of physical violence?

Yes

326 (80.7)

No

From your experience, who is, in general, most frequently physically harassed?

$77(19.1)$

Male

$105(26.0)$

Female

$221(54.9)$

Both

If you experience any form of physical violence, do you describe this/these experience/s as being very upsetting and of major importance?

Yes, all of them

$205(50.7)$

Yes, some of them

$128(31.7)$

No, not all

$71(17.6)$

TABLE 3: Physical violence among participants $(n=404)$.

\section{Academic violence among participants}

The prevalence of academic violence was $79 \%$. Approximately $37.1 \%$ of the participants reported their questions/queries were intentionally not answered, $33.7 \%$ reported they were asked to carry out some 


\section{Cureus}

personal services unrelated to patient care or educational activities, 33.2\% were excluded from otherwise reasonable learning opportunities offered to others, and $27.2 \%$ were forced to refer patients without providing a reasonable cause for referral. Academic violence had occurred more frequently in the surgery (16.3\%) and medicine departments (16.3\%). The main source of academic violence was consultants (45.5\%). During their career, $85.4 \%$ of the participants had witnessed an episode of academic violence, and they reported that both males and females were academically harassed with a similar frequency (74.0\%). The majority (44.1\%) of the participants reported that their experiences with academic violence were very upsetting and of major importance (Table 4).

\section{Variables}

Experienced academic violence

Did you experience any of the following forms of academic violence?

You were asked to carry out some personal services unrelated to patient care or educational activities

You were assigned tasks as punishment

Your questions/queries were intentionally not answered

You were excluded from otherwise reasonable learning opportunities that were offered to others

You were forced to refer patient without providing reasonable cause for referral

You were asked to take consent from very complicated cases

You were forced to do procedures that you were not mastering without supervision

You were forced to hold bleeps of senior doctor/s

You were threatened with failure or giving poor evaluations for reasons unrelated to your academic performance

Others

in which department/s these types of academic violence have happened more frequently?

Surgery

Medicine

Pediatrics

Oblgyn

Emergency

ICU

Psychiatry

Other

Who was/were the main source/s of academic violence?

Consultant

Specialist/registrars

Residents

Nurses

During your career, have you witnessed any episodes of academic violence?

From your experience, who is, in general, most frequently academically harassed? 


\section{Cureus}

Female

If you experience any form of academic violence, do you describe this/these experience/s as being very upsetting and of major importance?

TABLE 4: Academic violence among participants.

\section{Sexual harassment among participants}

Sexual harassment was reported by $76.5 \%$ of the participants. The most common form of sexual harassment was "received jokes or comments against your gender" (42.3\%) and "faced with an offensive body language” (39.6\%). Sexual harassment occurred more frequently in the surgery (36.1\%) and medicine departments (26.7\%). Patients or their relatives $(45.3 \%)$ and consultants $(40.1 \%)$ were the main sources of sexual harassment. The majority had witnessed an episode of sexual harassment during their career $(81.1 \%)$ and reported that females were most frequently sexually harassed $(56.9 \%)$. The majority (58.2\%) reported that their experiences with sexual harassment were very upsetting and of major importance (Table 5).

\section{Variables}

Did you experience any of the following forms of sexual harassment?

Received jokes or comments against your gender

Faced with offensive body language (e.g. repeated leering, standing too close)

In which department/s these types of sexual harassment have happened more frequently

ICU

Who was/were the main source/s of sexual harassment? 


\section{Cureus}

Nurses

$85(21.0)$

Patients or their relatives

$183(45.3)$

During your career, have you witnessed any episodes of sexual harassment?

Yes

$327(81.1)$

No

From your experience, who is, in general, most frequently sexually harassed?

Male

Female

230 (56.9)

Both

147 (36.4)

If you experience any form of sexual harassment, do you describe this/these experience/s as being very upsetting and of major importance?

Yes, all of them

235 (58.2)

Yes, some of them

117 (29.0)

No, not all

51 (12.6)

TABLE 5: Sexual harassment among participants $(n=404)$.

\section{Reporting violence and its effects on the participants}

Most participants agreed that mistreatment of hospital staff does exist (90.1\%). The majority (81.4\%) had experienced at least one of the mentioned types of violence, and 39.6\% did not complain or report the event to the authority. The most common reasons for not reporting were "reporting would not accomplish anything" (49.4\%), "reporting would become more troublesome than it was worth" (48.1\%), "I was afraid that reporting would adversely affect my evaluation or my professional career in the future" (30\%), "I was afraid that the reporting would not be kept confidential" (28.8\%), "I did not know to whom I should report or how to complain" (27.5\%) and "I was afraid of not being believed or the problem would not be dealt with fairly" (26.9\%). The majority (77.5\%) of the participants thought that violence is a big problem to be raised.

Most participants (77.0\%) agreed that the experience that they had during their career influenced their work practice, and $69.6 \%$ of them agreed that this experience affected their view of the health care profession. About half of the participants (49.8\%) said they would not advise any of their relatives to join any job related to health care (Table ๑).

In general, did you experience any of the mentioned types of violence?

If yes, how often did you complain or report the event to an authority?

If none, what was/were the reason/s for not reporting such experience 


\section{Cureus}

It was not significant to be reported to the authority

Reporting would not accomplish anything

Reporting would become more troublesome than it was worth

I dealt with the problem directly myself

I was afraid that reporting would adversely affect my evaluation or my professional career in the future

Do you think workplace violence is a big problem to be raised

Did the experience that you had during your career influence your work practice?

Did the experience affect your view of the health care profession?

If yes, have you advised any of your relatives not to join any job related to healthcare?

TABLE 6: Reporting workplace violence and its effects and influences on the participants $(n=404)$.

\section{The association between the demographics of the participants with workplace violence}

In this study, no significant association was found between the socio-demographical and work profile of the participants and the experience of violence.

\section{Discussion}

In this study, $81.4 \%$ of the participants experienced verbal, physical, academic, or sexual violence. This prevalence is higher than that found in previous similar studies conducted in Arar City and Abha City. In those studies, the prevalence of workplace violence among healthcare workers was $57.5 \%$ and $48.5 \%$ in Abha City [15] and Arar City [16], respectively. In other local studies that focused on a particular setting or occupation, the prevalence of workplace violence ranged between $90.7 \%$ in emergency departments in Tabuk [12] to $27.7 \%$ in primary care centers in Al-Hassa [14]. Internationally, the prevalence of workplace violence against healthcare workers was between $48.1 \%$ in Europe and $70.9 \%$ in Australia and New Zealand [8]. The high rates of violence against healthcare providers could be due to the nature of their jobs, which exposes them to work in close contact with people in times where they are in unstable conditions like confusion, aggression, or drug or alcohol intoxication [18,19]. Moreover, high levels of tension, stress, and anxiety during the time of admissions or hospital visits may contribute to this prevalence [20]. High expectations, increased demands, and long waiting times for the patients or their families were also found to cause violence [21]. These factors can explain the difference in workplace violence in different studies. For example, the difference between the prevalence found in this study (81.4\%) compared to the studies that were conducted in Abha City (57.5\%) [15] and Arar City (48.5\%) [16] could be attributed to the fact that Abha and Arar are peripheral cities in Saudi Arabia and they have a much smaller population compared to Riyadh, 
which could lead to their health centers being less overwhelmed with patients resulting in less waiting times, frustration, and violence from the patients.

Verbal violence was found to be the most common type of violence in this study with $79.5 \%$ of the participants reporting that they encountered verbal violence compared to $79 \%$ who encountered academic violence, $76.5 \%$ who encountered sexual harassment, and $67.6 \%$ who encountered physical violence. Verbal violence was also the most common type in Arar City, with $83 \%$ of those who were subjected to violence in that study being verbally abused [15]. Similarly, 55.9\% of violence victims were verbally abused in Abha City [16]. Verbal violence was also the most common type of workplace violence among healthcare workers in other Saudi studies [9-14], and it was found to be the most common type of violence in an international literature review that included studies from Asia, Europe, America, Africa, and Australia [8]. In this study, patients or their relatives were the main sources of violence of all violence categories (verbal, physical, and sexual) except academic violence in which consultants were the main source. This finding is consistent with previous local studies conducted in different settings [9-16], and international studies in Europe [22] and Canada [23], which arguably indicates the need for awareness programs targeting the general population regarding the negative impact of violence against healthcare providers on the quality of health care.

Participants in our study reported that they experienced verbal and physical violence mostly in the emergency department ( $40.3 \%$ and $18.1 \%$, respectively), while sexual harassment was frequently experienced in the surgery department (36.1\%), and academic violence was experienced in the medicine and surgery departments (16.3\%). Emergency departments were described to have high rates of violence against health care workers [24], perhaps due to overcrowding, long waiting times, and lack of privacy, which cause frustration and anger among patients [24]. Also, emergency departments have high rates of patients who come intoxicated [24].

Both males and females were perceived to being equally harassed in all categories of violence in our study, except sexual harassment in which females were perceived to be more frequently harassed by participants who have witnessed incidents of harassment. However, no statistically significant associations were found between gender and any type of violence. Previous studies were not consistent in finding an association between gender and workplace violence [25-27]. However, female healthcare providers were found to have a higher risk of sexual harassment than their male counterparts [28]. The absence of statistical associations between violence and the variables in this study indicates that all healthcare workers were subjected to violence regardless of their gender, age, specialty, nationality, years of experience, or job title. Accordingly, any effort to address violence among health care workers should arguably target everybody equally.

In this study, 39.6\% of the participants did not report the violence that they were subjected to because they thought "reporting would not accomplish anything" (49.4\%), or "reporting would become more troublesome than it was worth" (48.1\%). This could be due to the belief that violence in healthcare settings is "part of the job" or that the patients are not in full control of their actions, which are common reasons for not reporting [29]. Another common reason for not reporting violence in this study was "I was afraid that reporting would adversely affect my evaluation or my professional career in the future” (30\%). This could be attributed to the fear of retaliation, which was described as a reason for not reporting workplace violence in previous studies [30]. Similarly, healthcare workers in previous Saudi studies did not report the violent incidents that they encountered because they thought reporting was useless [15] or not an effective reaction [13]; while others did not report because they were afraid of the consequences of reporting [15] or had previous negative experiences were reporting did not accomplish anything [12]. This shows that there is a substantial need for hospitals to establish clear guidelines regarding workplace violence and outline how such violence would be handled by the institution. About one-third of the participants in this study reported that they "did not know to whom they should report or how to complain" (27.5\%), which obligates hospitals and health care settings to educate their employees regarding the reporting of workplace violence. We highly recommend that detailed information about workplace violence and how to report it should be incorporated into the orientation programs that are usually given to new employees at healthcare facilities across Saudi Arabia.

The majority (77\%) of the participants reported that their experience with workplace violence influenced their work practice. Previous studies have established an association between workplace violence and major occupational impacts like increased absence [6], wanting to quit [7], and less productivity [4]. According to a review published in 2014, up to $60 \%$ of those who were subjected to violence in the workplace thought about quitting their profession [3]. The duration of sick leaves taken by people who were subjected to violence was from 1 to 7 days [3]. We recommend that mental health services should be offered to healthcare workers who report incidents of workplace violence.

This study has some limitations. The fact that it is based on a survey, which subjects the results to selfreporting bias. Also, this study was conducted in only one medical city, which is considered another limitation.

\section{Conclusions}

High rates of workplace violence were found in this study. Approximately one-third of violence victims did not report the incidents thinking that "reporting would not accomplish anything", and another one-third of 
the victims did not know how to report, which requires healthcare facilities to establish clear guidelines and penalties for workplace violence. There is arguably an urgent need to develop programs that can reduce workplace violence and facilitate reporting it in hospitals. The majority of the participants reported that their experience with workplace violence influenced their work practice, which suggests that mental health services should be implemented for those who encountered workplace violence. Moreover, communitybased awareness programs regarding the negative impacts of violence against healthcare workers on the quality of care are needed due to the high prevalence of violence by patients or their relatives.

\section{Additional Information \\ Disclosures}

Human subjects: Consent was obtained or waived by all participants in this study. King Abdullah International Medical Research Center issued approval RYD-18-419812-203457. Animal subjects: All authors have confirmed that this study did not involve animal subjects or tissue. Conflicts of interest: In compliance with the ICMJE uniform disclosure form, all authors declare the following: Payment/services info: All authors have declared that no financial support was received from any organization for the submitted work. Financial relationships: All authors have declared that they have no financial relationships at present or within the previous three years with any organizations that might have an interest in the submitted work. Other relationships: All authors have declared that there are no other relationships or activities that could appear to have influenced the submitted work.

\section{References}

1. Flannery RB Jr: The employee victim of violence: recognizing the impact of untreated psychological trauma . Am J Alzheimers Dis Other Demen. 2001, 16:230-3. 10.1177/153331750101600406

2. Zafar W, Khan UR, Siddiqui SA, Jamali S, Razzak JA: Workplace violence and self-reported psychological health: coping with post-traumatic stress, mental distress, and burnout among physicians working in the emergency departments compared to other specialties in Pakistan. J Emerg Med. 2016, 50:167-77.e1. 10.1016/j.jemermed.2015.02.049

3. Lanctôt N, Guay S: The aftermath of workplace violence among healthcare workers: a systematic literature review of the consequences. Aggress Violent Behav. 2014, 19:492-501. 10.1016/j.avb.2014.07.010

4. Gates DM, Gillespie GL, Succop P: Violence against nurses and its impact on stress and productivity . Nurs Econ. 2011, 29:59-66, quiz 67.

5. Jaradat Y, Nielsen MB, Kristensen P, Nijem K, Bjertness E, Stigum H, Bast-Pettersen R: Workplace aggression, psychological distress, and job satisfaction among Palestinian nurses: A cross-sectional study. Appl Nurs Res. 2016, 32:190-8. 10.1016/j.apnr.2016.07.014

6. Fujishiro K, Gee GC, de Castro AB: Associations of workplace aggression with work-related well-being among nurses in the Philippines. Am J Public Health. 2011, 101:861-7. 10.2105/AJPH.2009.188144

7. Alameddine M, Mourad Y, Dimassi H: A national study on nurses' exposure to occupational violence in Lebanon: prevalence, consequences and associated factors. PLoS One. 2015, 10:e0137105. 10.1371/journal.pone.0137105

8. Liu J, Gan Y, Jiang H, et al.: Prevalence of workplace violence against healthcare workers: a systematic review and meta-analysis. Occup Environ Med. 2019, 76:927-3. 10.1136/oemed-2019-105849

9. Alkorashy HA, Al Moalad FB: Workplace violence against nursing staff in a Saudi university hospital . Int Nurs Rev. 2016, 63:226-32. 10.1111/inr.12242

10. Mohamed AG: Work-related assaults on nursing staff in Riyadh, Saudi Arabia . J Family Community Med. 2002, 9:51-6.

11. Alhusain F, Aloqalaa M, Alrusayyis D, et al.: Workplace violence against healthcare providers in emergency departments in Saudi Arabia. SA J Emerg Med. 2020, 1:5-14. 10.24911/sjemed/72-1571404869

12. Alzahrani T, Almutairi A, Alamri D, et al.: Violence and aggression toward health care professionals in emergency departments in Tabuk, Saudi Arabia. EJPMR. 2016, 3:05-11.

13. Al-Turki N, Afify AA, AlAteeq M: Violence against health workers in Family Medicine Centers . J Multidiscip Healthc. 2016, 9:257-66. 10.2147/JMDH.S105407

14. El-Gilany AH, El-Wehady A, Amr M: Violence against primary health care workers in Al-Hassa, Saudi Arabia . J Interpers Violence. 2010, 25:716-34. 10.1177/0886260509334395

15. Al Anazi RB, AlQahtani SM, Mohamad AE, Hammad SM, Khleif H: Violence against health-care workers in governmental health facilities in Arar City, Saudi Arabia. ScientificWorldJournal. 2020, 2020:6380281. 10.1155/2020/6380281

16. Alsaleem SA, Alsabaani A, Alamri RS, et al.: Violence towards healthcare workers: a study conducted in Abha City, Saudi Arabia. J Family Community Med. 2018, 25:188-93. 10.4103/ffcm.JFCM_170 17

17. Al-Shafaee M, Al-Kaabi Y, Al-Farsi Y, White G, Al-Maniri A, Al-Sinawi H, Al-Adawi S: Pilot study on the prevalence of abuse and mistreatment during clinical internship: a cross-sectional study among first year residents in Oman. BMJ Open. 2013, 3:e002076. 10.1136/bmjopen-2012-002076

18. Vezyridis P, Samoutis A, Mavrikiou PM: Workplace violence against clinicians in Cypriot emergency departments: a national questionnaire survey. J Clin Nurs. 2015, 24:1210-22. 10.1111/jocn.12660

19. Pompeii LA, Schoenfisch AL, Lipscomb HJ, Dement JM, Smith CD, Upadhyaya M: Physical assault, physical threat, and verbal abuse perpetrated against hospital workers by patients or visitors in six U.S. hospitals. Am J Ind Med. 2015, 58:1194-204. 10.1002/ajim.22489

20. AbuAlRub RF, Al Khawaldeh AT: Workplace physical violence among hospital nurses and physicians in underserved areas in Jordan. J Clin Nurs. 2014, 23:1937-47. 10.1111/jocn.12473

21. Baykan Z, Öktem İs, Çetinkaya F, Naçar M: Physician exposure to violence: a study performed in Turkey . Int J Occup Saf Ergon. 2015, 21:291-7. 10.1080/10803548.2015.1073008 


\section{Cureus}

22. Kvas A, Seljak J: Sources of workplace violence against nurses . Work. 2015, 52:177-84. 10.3233/WOR-152040

23. Duncan SM, Hyndman K, Estabrooks CA, et al.: Nurses' experience of violence in Alberta and British Columbia hospitals. Can J Nurs Res. 2001, 32:57-78.

24. Tadros A, Kiefer C: Violence in the emergency department: a global problem . Psychiatr Clin North Am. 2017, 40:575-84. 10.1016/j.psc.2017.05.016

25. Cavalcanti AL, Belo ED, Marcolino ED, et al.: Occupational violence against Brazilian nurses. Iran J Public Health. 2018, 47:1636-43.

26. Seun-Fadipe CT, Akinsulore AA, Oginni OA: Workplace violence and risk for psychiatric morbidity among health workers in a tertiary health care setting in Nigeria: prevalence and correlates. Psychiatry Res. 2019, 272:730-6. 10.1016/j.psychres.2018.12.177

27. Serafin LI, Czarkowska-Pączek B: Prevalence of bullying in the nursing workplace and determinant factors: a nationwide cross-sectional Polish study survey. BMJ Open. 2019, 9:e033819. 10.1136/bmjopen-2019033819

28. Friborg MK, Hansen JV, Aldrich PT, et al.: Workplace sexual harassment and depressive symptoms: a crosssectional multilevel analysis comparing harassment from clients or customers to harassment from other employees amongst 7603 Danish employees from 1041 organizations. BMC Public Health. 2017, 17:675. 10.1186/s12889-017-4669-X

29. Phillips JP: Workplace violence against health care workers in the United States . N Engl J Med. 2016, 374:1661-9. 10.1056/NEJMra1501998

30. Stene J, Larson E, Levy M, Dohlman M: Workplace violence in the emergency department: giving staff the tools and support to report. Perm J. 2015, 19:e113-7. 10.7812/TPP/14-187 